\title{
World Health Organization and Global Health Policy
}

\author{
Susan C. Vonderheid, Naeema Al-Gasseer
}

Journal of Nursing Scholarship, 2002; 34:2, 109-110. @2002 Sigma Theta Tau International.

[Key words: World Health Organization, health policy]

$\mathrm{T}$

he World Health Organization (WHO) was founded in 1948 as a special agency of the United Nations.

The WHO goal is "the attainment by all peoples of the highest possible level of health" (WHO, 1999, p.2). To achieve this objective, the main functions of WHO are to direct and coordinate international health work by setting standards and guidelines and to provide technical assistance in cooperation with countries to strengthen national health programs.

Nurses and midwives around the world can benefit from knowledge of WHO and its functions in setting health policy. Thus this paper is focused on promoting understanding of WHO in global health policy and increasing awareness of the World Health Assembly (WHA) resolutions that influence nursing and midwifery.

\section{WHO Structure and Functions}

The work of the WHO is carried out in three structures: the WHA, executive board (EB), and secretariat (WHO, 1999). The WHA is the supreme governing body composed of delegates from each member state; it meets each year in May. Members are countries that belong to the United Nations and accept the constitution of WHO.

Currently 191 member states constitute the WHA. Each member state is represented by not more than three delegates and has one vote. Delegates are representatives of their governments and they convey the positions of the government. The functions of the WHA vary, but the most important function is to determine policies of the $\mathrm{WHO}$, including the supervision of financial policies and approval of the program of work and budget. The WHA also has the authority to adopt conventions, agreements, or resolutions relevant to WHO's mandate of "Health for All."

The EB consists of 32 people who serve 3 years and may be reelected. With consideration of equitable geographic representation, WHA representatives elect member states entitled to designate their representatives to serve on the EB. The main functions of the EB are to implement the decisions and policies of the WHA, to provide advice or proposals, and to forward with comments and amendments the program of work and budget prepared jointly by the secretariat and member states for WHA's consideration and decision.
The secretariat is composed of the director general (DG) and technical and administrative staff required to carry out the work of WHO. The DG is the chief technical and administrative officer of WHO, as well as ex-officio member of the WHA, $\mathrm{EB}$, commissions, committees, and conferences convened by WHO. The current DG is Gro Harlem Brundtland from Norway, the first woman to hold this post. The secretariat is staffed by approximately 4,000 experts in health and related areas working at headquarters or at regional or country levels.

WHO headquarters is located in Geneva, Switzerland and a regional office is located in each of six geographic regions: Africa (AFRO), the Americas (AMRO/PAHO), the Eastern Mediterranean (EMRO), Europe (EURO), South-East Asia (SEARO), and Western Pacific (WPRO). The role of the secretariat and technical officers for each region is to support member states in their actions for health and to facilitate cooperation among member states and between $\mathrm{WHO}$ and member states.

\section{WHA Resolutions and the Policy Process}

WHA resolutions shape health policy at international, country, and community levels. Resolutions of the assembly and board are "formally adopted expressions of the opinion, will, or decision of a constitutional organ or the WHO and may be considered legal texts" (WHO, 1995, p. 12). Resolutions include the preamble or problem statement, with reasons for taking designated actions, and the description of actions being taken or recommended. The policy cycle begins with generating a resolution prepared jointly by the secretariat and member states, followed by passage of this international agreement by the EB and then by the WHA.

Susan C. Vonderheid, RN, PhD, Rho, Research Fellow, University of Michigan, Ann Arbor Michigan; Naeema Al-Gasseer, RN, PhD, Alpha Lambda, Senior Scientist for Nursing and Midwifery, World Health Organization, Geneva, Switzerland. Preparation of this manuscript was supported in part by a National Institute of Nursing Research Primary Health Care Training Grant (T32 NRO 7079) to the University of Illinois at Chicago College of Nursing and its WHO Collaborating Center for International Development in Primary Health Care. Correspondence to Dr. Al-Gasseer, WHO, 1211 Geneva, Switzerland. E-mail: algasseern@who.int or Dr. Vonderheid, 218 South Calumet, Aurora, IL 60506. E-mail: vonde@umich.edu

Accepted for publication January 15, 2002. 
Because the first resolution on nursing and midwifery was passed by WHA in 1948, a total of 13 resolutions relevant to nursing and midwifery have passed. In more than 50 years, the issues addressed in these resolutions have changed only minimally. Key issues include: the provision of health care by qualified personnel to meet health needs; workforce issues related to inadequate supply and deployment of personnel, and working conditions; education and its relationship to competent providers; regulations and legislation for training and practice; resources and opportunities such as fellowships for nurses and midwives at all levels of WHO; participation of nurses and midwives at national policy levels and in health research; and promotion of interdisciplinary collaboration.

An example is Resolution WHA49.1: "Strengthening Nursing and Midwifery," passed in 1996. The preamble indicates the rationale, including the need for focus on progress related to nursing and midwifery services toward achieving health for all, heightened awareness of problems in health and social development, increased momentum for changes brought about by international conferences, concerns about the emergence of new diseases and the reemergence of old ones, and recognition of the potential contributions of nurses and midwives in improving health system performance. The operative section indicates recommended actions to be carried out in member states:

- include nurses and midwives in health policy at national levels;

- develop national plans for nursing and midwifery services;

- monitor and evaluate progress toward national health priorities through the effective use of nurses and midwives;

- strengthen education and practice in primary health care; and

- increase fellowship opportunities for nurses and midwives. The director general was requested to execute these activities:

- increase support to countries for developing, implementing, and evaluating national plans for health to include nursing and midwifery;

- promote coordination among organizations to support national plans and effective use of resources, including nurses and midwives;

- promote and support training in research methodology for nurses and midwives;

- provide for the work of the Global Advisory Group for Nursing and Midwifery; and

- report progress made on implementing WHA49.1 at the 54th Assembly in 2001.

This example shows that many people at all levels participate in and are affected by resolutions of the WHA. The WHO technical officer responsible for the report is the Senior Scientist for Nursing and Midwifery in collaboration with regional advisors for nursing and midwifery compiles information to create the "big picture" or the global and regional context for the country, community, and project. Other participants include experts in nursing and midwifery from different regions, representatives of countries such as chief nurses, and representatives of international organizations, such as the International Council of Nurses, the International Confederation of Midwives, Sigma Theta Tau International, and the International Red Cross.

\section{Opportunities for Influence on Health Policy}

Improving overall health and reducing health inequities worldwide require changes in nursing and midwifery. As the largest group of health care providers and the largest proportion of providers of care to underserved populations, nurses and midwives have great potential to improve global health (WHO, 1996). This potential is magnified by the reality that the underserved and people without care are most likely to live at or near poverty levels and bear disproportionate burdens of disease (Global Health Forum, 2000). WHA resolutions are opportunities for nurses and midwives to present unified messages to promote change.

Nurses and midwives can contribute to developing and passing strong, meaningful resolutions in several ways. First, standard definitions and indicators of nursing and midwifery are needed worldwide. For example, the definitions and expected competencies of "nurse" and "midwife" require examination and consensus so that comparisons among various populations are possible. Second, evidence of the effects of nursing and midwifery care on health outcomes is needed. This evidence includes improved dissemination of current research and greater overall production of conceptually and methodologically sound research. Research aimed at priority health problems, processes, and outcomes amenable to nursing and midwifery intervention is critical. Such research should include both policy implications and cost analyses related to the short- and long-term outcomes of nursing and midwifery care.

Third, greater participation is needed to advocate for policy to strengthen nursing and midwifery education, practice, and research. Achieving this goal requires that nurses and midwives talk with policymakers and participate in various public forums where health-related issues are discussed. A strategy based on information about population health, evidence from practice, and widescale participation is essential for influencing policy decisions.

\section{Conclusions}

The $\mathrm{WHO}$ and its constituent units are a unique force in shaping global health policy and influencing health of populations, including resolutions and actions pertaining to nursing and midwifery. Nurses and midwives along with other health care professionals around the world can and should participate in actions to promote health for all.

\section{References}

Global Forum for Health Research. (2000). The 10/90 report on health research 2000. Geneva, Switzerland: Author.

World Health Organization. (1996). Nursing practice, WHO technical report series, 860. Geneva, Switzerland: Author.

World Health Organization. (1999). Basic documents, 42nd ed. Geneva, Switzerland: Author.

World Health Organization. (2000). WHO manual. Geneva, Switzerland: Author. 